(C) The Authors 2015. This is an Open Access article, distributed under the terms of the Creative Commons Attribution licence (http://creative commons.org/licenses/by/3.0/), which permits unrestricted re-use, distribution, and reproduction in any medium, provided the original work is properly cited.

\title{
Effect of bovine colostrum feeding in comparison with milk replacer and natural feeding on the immune responses and colonisation of enterotoxigenic Escherichia coli in the intestinal tissue of piglets
}

\author{
Sugiharto Sugiharto ${ }^{1,2}$, Ann-Sofie Riis Poulsen ${ }^{1}$, Nuria Canibe ${ }^{1}$ and Charlotte Lauridsen ${ }^{1 *}$ \\ ${ }^{1}$ Department of Animal Science, Faculty of Science and Technology, University of Aarbus, 8830 Tjele, Denmark \\ ${ }^{2}$ Faculty of Animal and Agricultural Sciences, Diponegoro University, Semarang, Central Java 50275, Indonesia \\ (Submitted 4 April 2014 - Final revision received 12 August 2014 - Accepted 8 September 2014 - First published online 6 March 2015)
}

Abstract

The present study investigated the effect of feeding bovine colostrum (BC) to piglets in comparison with feeding a milk replacer (MR) and conventional rearing by the sow on the intestinal immune system and number of enterotoxigenic Escherichia coli (ETEC) colonising the intestinal tissue. Piglets (23-d-old) were allocated to one of the following four groups: (1) killed at the beginning of the experiment (Base); (2) separated from the sow and fed BC (BC-fed); (3) separated from the sow and fed a MR (MR-fed); (4) kept with the sow (Sow-Milk). Blood was sampled on days 1 and 8 , and faecal samples were collected on days 1, 3, 5 and 8 . On day 8, piglets were killed and gastrointestinal digesta and intestinal segments were collected. The frequency of diarrhoea was found to be higher $(P \leq 0 \cdot 019)$ in MR-fed piglets than in BC-fed and Sow-Milk piglets. Piglets from the MR-fed group had the lowest lactic acid bacteria:haemolytic E. coli ratio $\left(P_{\text {treat }}=0.064\right)$ in the faeces. The number of $E$. coli colonising the intestinal tissue was higher $(P<0.001)$ in piglets from the MR-fed group than in those from the BC-fed and Sow-Milk groups. Piglets from the Sow-Milk group had a higher $(P=0 \cdot 020)$ mucosal IgG concentration than those from the MR-fed group, but did not exhibit any difference when compared with piglets from the Base and BC-fed groups. Piglets from the BC-fed group exhibited a reduced $(P \leq 0.037)$ expression level of Toll-like receptor-4 in the intestinal mucosa when compared with those from the MR-fed and Sow-Milk groups. The expression level of $I L-2$ was higher $(P \leq 0 \cdot 051)$ in piglets from the MR-fed group than in those from the other treatment groups. In conclusion, feeding BC rather than MR to the piglets reduced the colonisation of intestine by ETEC and modulated the intestinal immune system, whereas no differences were observed in piglets fed BC and conventionally reared by the sows.

\section{Key words: Bovine colostrum: Diarrhoea: Enterotoxigenic Escherichia coli: Intestinal immunity: Weak piglets}

Increasing the litter size has long been a goal among pig producers, as the number of offspring born is an important economic trait. Initially, improvements made in management and nutrition were aimed at increasing the litter size, and more recently, genetic selection for litter size has been implemented $^{(1)}$. It has been reported that an increased litter size is genetically associated with a decreased mean birth weight and an increased within-litter birth weight variation ${ }^{(2)}$. Therefore, the use of hyperprolific sows in the pig industry not only results in large litters, but also leads to an increase in the number of supernumerary and underprivileged piglets (underweight at birth, referred here as weak piglets) ${ }^{(3)}$.

Apart from its value as a complete nutrient source, milk contains a wide range of factors (e.g. antibodies and cytokines) that can modulate the development and maturation of the immune system and subsequently the immune response of piglets ${ }^{(4,5)}$ During lactation, lower milk supply per piglet is often observed in large litters. This particularly occurs after the maximal milk production capacity is attained $(7-15 \mathrm{~d})^{(6)}$. Given that weak piglets have a lower ability to compete for the udder ${ }^{(7)}$ and are often less vigorous in suckling ${ }^{(6)}$, their milk intake may be insufficient ${ }^{(7)}$. Hence, it is not surprising that weak piglets have a poor pre-weaning growth performance and often fail to thrive, or even die, by the time of weaning ${ }^{(8)}$. It has been suggested that low body weight and immunoincompetence at weaning adversely affect the growth performance and viability of piglets after weaning ${ }^{(7,9,10)}$. Thus, efforts to enhance the growth and survival of weak piglets after weaning should be aimed at improving not only the weaning weight, but also the health and immunity ${ }^{(11)}$.

Abbreviations: Base, piglets killed at the beginning of the experiment; BC, bovine colostrum; BC-fed, piglets separated from the sow and fed bovine colostrum; cfu, colony-forming units; DMEM, Dulbecco's modified Eagle's medium; GIT, gastrointestinal tract; LAB, lactic acid bacteria; MR, milk replacer; MR-fed, piglets separated from the sow and fed a milk replacer; PIOC, porcine intestinal organ culture; Sow-Milk, piglets kept with the sow; $T G F-\beta 1$, transforming growth factor- $\beta 1$.

* Corresponding author: C. Lauridsen, fax +45 87154249, email charlotte.lauridsen@anis.au.dk 
Bovine colostrum (BC), which is a commercially available co-product from the dairy industry, is known to contain several growth factors as well as antimicrobial and immunomodulatory components essential for host development and defence functions $^{(4)}$. Of the bioactive components, Ig, especially $\operatorname{IgG}$, appear to be the most important immune components present in $\mathrm{BC}$ as they represent $70-80 \%$ of the total protein content in the colostrum ${ }^{(4)}$. Bovine colostral Ig provide the host with passive immunity ${ }^{(12,13)}$ and, in concert with lactoferrin, lactoperoxidase and lysozyme, may act as antimicrobial agents ${ }^{(4)}$. BC also contains high amounts of cytokines that can modulate the development and maturation of the immune system ${ }^{(4,5)}$. Besides the provision of supplemental milk during suckling ${ }^{(11)}$, artificial rearing on milk replacers $(\mathrm{MR})^{(3)}$ has been reported as a good alternative for raising low-birth-weight piglets before weaning. Taking this into consideration, rearing weak piglets artificially on $\mathrm{BC}$ could be expected to improve the growth performance as well as to boost the immune system before weaning. The aim of the present study was to investigate the effect of feeding a commercial BC product to piglets in comparison with feeding a common MR and conventional rearing by the sow on the intestinal immune system and colonisation of ETEC in the intestinal tissue. Our hypothesis was that BC would be a better source than MR and as good as conventional rearing by the sow in terms of optimisation of the immune defence and intestinal health of weak piglets.

\section{Materials and methods}

\section{Experimental design}

The present experiment was conducted according to the licence obtained from the Danish Animal Experiments Inspectorate, Ministry of Food, Agriculture and Fisheries, Danish Veterinary and Food Administration.

A total of forty piglets $(8.30 \quad(\mathrm{SD} 1.45) \mathrm{kg}$ ) from four litters obtained from the herd at the Faculty of Science and Technology, Aarhus University, Foulum (Denmark), were used in the present experiment. All piglets were from sows tested homozygote carriers of the dominant gene encoding for the intestinal F18 fimbriae receptors (a DNA marker genotyping-based test was performed on DNA extracted from hair samples by van Haeringen laboratorium b.v., Wageningen, The Netherlands); thus, piglets used in the present study were susceptible to Escherichia coli F18. Piglets were provided neither additional milk nor creep feed from birth to weaning (separation from the sow).

Of the forty piglets, four piglets, one from each litter, were killed at the beginning of the experiment (Base) and thirty-six piglets, nine per litter, were kept alive and randomly allocated to one of the following three treatment groups: (1) separated from the sow and fed a commercial BC product (BC-fed); (2) separated from the sow and fed a commercial MR (MR-fed); (3) kept with the sow (Sow-Milk). Piglets from the BC-fed and MR-fed groups were separated from the sows at $23 \mathrm{~d}$ of age, transferred to the experimental stable and provided either skimmed standardised BC (European Colostrum Industry S. A.) or a commercial MR (Vitfoss) ad libitum
Table 1. Chemical composition of the bovine colostrum (BC), milk replacer (MR) and sow milk

\begin{tabular}{lccc}
\hline Items & BC $^{\star}$ & MR $^{\star}$ & Sow milk† \\
\hline DM (\%) & 96.1 & 95.0 & 17.9 \\
Crude protein (\% DM) & 71.0 & 23.3 & 28.5 \\
Crude fat (\% DM) & 2.1 & 13.9 & 36.3 \\
Ash (\% DM) & 6.2 & 7.2 & 5.6 \\
Ig (\% DM) & & & \\
IgG & 38.4 & 0.05 & 0.11 \\
IgA & 3.59 & 0.01 & 2.18 \\
IgM & 2.52 & ND & 0.56 \\
\hline
\end{tabular}

$\mathrm{ND}$, not detected (detection level $=78 \mathrm{ng} / \mathrm{ml}$, equivalent to $0.00001 \%$ ).

${ }^{*}$ Chemical analyses of BC and MR were performed by Eurofins Steins Laboratorium A/S, Odense, Denmark.

†The chemical compositions of sow milk, especially DM, protein and fat, are adopted from Lauridsen \& Danielsen ${ }^{(38)}$, while that of ash is adopted from Aguinaga et al. ${ }^{(39)}$.

¥ The concentrations of Ig were determined in our laboratory. Values of Ig for sow milk are the average values from four milk samples (obtained from four sows)

for $8 \mathrm{~d}$. The chemical composition of the sow milk, BC and $\mathrm{MR}$ is given in Table 1. Liquid $\mathrm{BC}$ and $\mathrm{MR}$ were prepared using an automated wet feeder (Mambo Automix 25; Wit-Mambo, Inc.), in which $\mathrm{BC}$ and $\mathrm{MR}$ powders were automatically mixed with warm water $\left(45^{\circ} \mathrm{C}\right.$; approximately $150 \mathrm{~g}$ of powder in 1 litre of water) and given to the piglets on a regular basis. To help the piglets become familiar with the automated wet feeder and stimulate the consumption of liquid BC or MR, sow milk collected from the corresponding sow was fed to the piglets using the feeder upon arrival to the experimental stable. Piglets from the Sow-Milk group were kept with their dams in the farrowing unit until the end of the experiment without any supplementary feed or milk. To minimise the variation among the treatment groups in terms of stress caused by separation from the sow, piglets from the Sow-Milk group were transported in a similar manner to those in the other groups and returned to the sows again.

A total of three littermates of similar weight were housed together in $1.45 \times 1.70 \mathrm{~m}^{2}$ pens with rubber mat and sawdust bedding. Each pen was equipped with an automated wet feeder and a water nipple giving permanent free access to feed and water to all the three piglets. Temperature in the experimental stable was maintained at $24^{\circ} \mathrm{C}$ throughout the experiment and the pens were equipped with a heat lamp. To reduce the impact of moving BC-fed and MR-fed piglets from the sows when compared with Sow-Milk piglets regarding microbial contamination from the environment, material (a mixture of bedding and faeces) from the floor of pens where the sows were housed was collected daily and spread in the corresponding pens where BC-fed and MR-fed piglets were housed. In this way, all piglets were continuously exposed to the microbiota of sow faecal origin.

\section{Sampling and data collection}

The body weight of each piglet was recorded at the beginning (day 1 ) and at the end (day 8) of the experiment. BC and MR consumption was measured by recording the weight of the 
powder provided to the piglets and any unconsumed residue on a daily basis. For Ig analyses, blood samples were collected in heparinised Vacutainer tubes by puncture of the jugular vein of each piglet on days 1 and 8. Plasma was obtained after centrifugation of blood samples at $2000 \boldsymbol{g}$ for $10 \mathrm{~min}$ and stored at $-20^{\circ} \mathrm{C}$ until analysis. Faecal samples were collected from the rectum of each piglet on days $1,3,5$ and 8 of the experiment. Rectal temperature was recorded with a digital thermometer (Kruuse) before faecal sample collection. The consistency of faecal samples $(1=$ hard, dry and cloddy; $2=$ firm; $3=$ soft with shape; $4=$ soft and liquid; $5=$ watery and dark; $6=$ watery and yellow; and $7=$ foamy and yellow), used as an indicator of the occurrence of diarrhoea, was recorded immediately after sample collection. A faecal consistency score $>3$ was defined as clinical signs of diarrhoea ${ }^{(14)}$. The frequency of diarrhoea was calculated by counting pig days with a diarrhoea score $>3$. The alertness score ( $0=$ normal and $1=$ depressed or listless $)$ of each piglet was also assessed visually throughout the experiment.

One piglet per litter (four in total) was killed using a captive bolt gun at the beginning of the experiment (day 1) and one piglet per litter and treatment (12 in total) was killed at the end of the experiment (day 8). The abdomen was incised and gall bladder (for bile collection) was obtained immediately after bleeding the animal. The gastrointestinal tract (GIT) was immediately removed and divided into five segments (stomach, proximal and distal small intestine, caecum and mid-colon), and digesta from each segment was collected for bacterial enumeration. The length of the small intestine, from the pyloric sphincter to the ileocolonic junction, was measured before digesta collection. Approximately $15 \mathrm{~cm}$ segments from 10\% (representing duodenum), 50\% (jejunum) and $90 \%$ (ileum) of the length of the small intestine measured from the duodenum were removed, opened lengthways and washed with ice-cold PBS. Mucosa was collected from these segments by gently scraping with a glass microscope slide and immediately stored at $-20^{\circ} \mathrm{C}$ until $\mathrm{Ig}$ analyses. For gene expression analyses, mucosa (approximately $100 \mathrm{mg}$ ) collected from the same sites of the small intestine (jejunum and ileum) was preserved in the RNAlater ( $1 \mathrm{ml}$; Sigma-Aldrich) and stored at $4^{\circ} \mathrm{C}$ for $1 \mathrm{~d}$ before storage at $-20^{\circ} \mathrm{C}$. Intestinal segments (jejunum and ileum) were also collected from piglets killed at the end of the experiment and used in the porcine intestinal organ culture (PIOC) experiment.

\section{Porcine intestinal organ culture experiment}

A total of twelve piglets, one per litter and treatment, were used in the PIOC experiment. Immediately after incising the abdomen and bleeding the animal, three jejunal segments and three ileal segments $(15 \mathrm{~cm}$ each) were collected aseptically, immersed in Dulbecco's modified Eagle's medium (DMEM), kept on ice and immediately used in the PIOC experiment. E. coli F18 inoculum was prepared by retrieving the bacterial culture stored at $-80^{\circ} \mathrm{C}$, streaking on blood agar (Oxoid, Deutschland $\mathrm{GmbH}$ ) and culturing at $37^{\circ} \mathrm{C}$ for 18h. A loopful of E. coli F18 colony was taken from blood agar and suspended in $4 \mathrm{ml}$ of PBS. The suspension $(0 \cdot 1 \mathrm{ml})$ was poured onto Iso-Sensitest agar (Oxoid) and incubated at $37^{\circ} \mathrm{C}$ overnight. PBS $(10 \mathrm{ml})$ was poured into the incubated plate, and the agar surface was gently rubbed with a sterile Drigalski spatula to remove the bacterial colonies from the agar plate. The bacterial suspension was transferred into a sterile tube and diluted 1:20 (v/v) with DMEM to obtain an inoculum of $5 \times 10^{8}$ colony-forming units $(\mathrm{cfu}) / \mathrm{ml}$ before being used for inoculating the intestinal segments of piglets. The E. coli F18 strain was isolated at the Danish Veterinary Institute (Frederiksberg, Copenhagen, Denmark) from the intestinal content of a pig with post-weaning diarrhoea. It was found to harbour genes for enterotoxins heat stable toxin b (STb), heat labile toxin (LT), Enteroaggregative Escherichia coli heat-stable enterotoxin 1 (EAST1), Shiga toxin 2e and fimbriae F18. The bacteria were found to be haemolytic when grown on blood agar (Oxoid) ${ }^{(15)}$.

Of the collected jejunal and ileal segments, two pieces were inoculated with E. coli F18 and one piece was used as a control (not inoculated). The PIOC experiment was conducted based on the model described by Naughton et al. ${ }^{(16)}$ and modified by Sugiharto et al. ${ }^{(17)}$. In brief, polyethylene tubing (Siltube; Eurpharm; $6 \mathrm{~mm}$ in diameter) was inserted into either end of the segment and tied with a suture to keep the tubing in place. The tissue was washed with $50 \mathrm{ml}$ of PBS (pH 7-2) using a Fill-Master pump (Type 311; Delta Scientific Medical; flow rate of $7.7 \mathrm{~cm} / \mathrm{s}$ ). The other end of the segment was tied, $10 \mathrm{ml}$ of DMEM alone (control) or DMEM containing E. coli $\mathrm{F} 18$ was inoculated, and the segment was sealed with a Teflon plug ( $5 \mathrm{~mm}$ in diameter). The segment was immersed in DMEM in a $300 \mathrm{ml}$ infusion bottle in a shaking water-bath at $37^{\circ} \mathrm{C}$, removed after $1.5 \mathrm{~h}$ and washed with $50 \mathrm{ml}$ of PBS after removing the content. Mucosa was collected from a piece of the segment and preserved in the RNAlater for gene expression analyses. The remaining segment was weighed and homogenised (Janke-Kunkel Ultra-Turrax T25 homogeniser; Bie\&Bentsen a/s) for $20 \mathrm{~s}$ in PBS. E. coli were enumerated on MacConkey agar (Merck KGaA) after aerobic incubation at $37^{\circ} \mathrm{C}$ overnight.

\section{Microbiological analyses of the faecal and digesta samples}

Microbiological analyses were performed on faecal samples (collected daily from one piglet per pen) and digesta samples collected from piglets that were killed at the end of the experiment. Approximately $1 \mathrm{~g}$ of faeces and $10 \mathrm{~g}$ of digesta were suspended in a pre-reduced salt medium ${ }^{(18)}$ and homogenised in a laboratory paddle blender (Seward Stomachers ${ }^{\circledR} 80$ Biomaster; Lab System) for $2 \mathrm{~min}$. Serial 10-fold dilutions were then prepared in the same medium and samples $(0.1 \mathrm{ml})$ were plated on selective media. Haemolytic E. coli and coliform bacteria were enumerated on blood agar (Oxoid) and MacConkey agar (Merck), respectively, after aerobic incubation at $37^{\circ} \mathrm{C}$ for $1 \mathrm{~d}$, whereas lactic acid bacteria (LAB) were enumerated on de Man-Rogosa-Sharpe agar (Merck) after anaerobic incubation at $37^{\circ} \mathrm{C}$ for $3 \mathrm{~d}$. 
The number of E. coli and LAB is presented as the LAB:haemolytic $E$. coli ratio or the LAB:total coliform bacteria ratio.

\section{Immunoglobulin analyses}

The concentrations of total IgG, IgA and IgM in the mucosa, plasma and sow milk and those of IgA and IgM in bile were measured using the pig Ig ELISA quantification kit (Bethyl Laboratories). The same Ig types were measured in the skimmed standardised BC and commercial MR using the bovine Ig ELISA quantification kit (Bethyl Laboratories). All assays were performed according to the manufacturer's instructions and run in duplicates. The intra-assay (withinplate) $\mathrm{CV}$ for the ELISA was $0 \cdot 1-12.5 \%$ and the inter-assay (between-plate) CV was $0 \cdot 2-12 \cdot 3 \%$. Before the assays, the mucosa samples were vortexed in PBS $(1: 10, \mathrm{w} / \mathrm{w})$ for $60 \mathrm{~s}$ and centrifuged at $2000 \mathrm{~g}$ for $10 \mathrm{~min}$ and the supernatant was obtained and used for the determination of Ig concentrations and total protein content. The concentration of IgA in the intestinal mucosa is expressed as the relative amount of IgA to that of total protein. Total protein content in the mucosa was quantified using the Advia 1650 autoanalyser (Siemens Medical Solutions).

\section{Gene expression analyses}

The mucosa was homogenised by transferring it into a lysis buffer (Macherey-Nagel GmbH \& Co. KG) and treated with a rotor-stator homogeniser (TissueLyser LT; Qiagen GmbH) until it was uniformly homogeneous. Total RNA was isolated using the NucleoSpin RNA kits (Macherey-Nagel) according to the manufacturer's protocols. The quality and quantity of RNA were assessed using agarose gel electrophoresis and a spectrophotometer (NanoDrop ND-1000; Saveen Werner), respectively. All samples were adjusted to $200 \mathrm{ng} / \mu \mathrm{l}$ and converted into complementary DNA using the High Capacity
cDNA Reverse Transcription Kit (Invitrogen) according to the manufacturer's instructions. All PCR were run in 384-well plates by mixing $2 \mu \mathrm{l}$ of complementary DNA with $8 \mu \mathrm{l}$ of the mix containing the primers, the probe and $2 \times$ TaqMan Master Mix (catalogue no. 4324018; Applied Biosystems) (Table 2). The reactions were run in duplicate for the target genes and triplicate for the housekeeping gene under standard amplification conditions determined for the Applied Biosystem ViiA 7 Real-Time PCR system (Life Technologies). Gene expression cycle threshold $\left(C_{\mathrm{t}}\right)$ values were recorded using the Applied Biosystem ViiA 7 software. Glyceraldehyde-3-phosphate dehydrogenase (GAPDH) was used as the housekeeping gene. The $C_{\mathrm{t}}$ value for the target genes of each sample was corrected by subtracting the $C_{\mathrm{t}}$ value of the $G A P D H$ gene from the $C_{\mathrm{t}}$ value of the corresponding gene $\left(\Delta C_{\mathrm{t}}\right)$. The samples collected from the jejunal mucosa of Base piglets were used as the reference samples, and the $\Delta C_{\mathrm{t}}$ value of all the samples was subtracted from the average $\Delta C_{\mathrm{t}}$ value of the reference samples $\left(\Delta \Delta C_{\mathrm{t}}\right)$. The fold change in the expression of each target gene was calculated using the following formula: $2^{-\Delta \Delta C_{\mathrm{t}}}$.

\section{Calculations and statistical analyses}

Data on weight gain, frequency of diarrhoea, rectal temperature, alertness score and plasma Ig concentrations were obtained from each piglet, while data on microbial counts, mucosal and biliary Ig concentrations, and gene expression levels were obtained from one piglet per pen. Bacterial population counts (cfu) were normalised using log transformation, and data on weight gain of each piglet were collected per pen before analysis. Data on bacterial counts obtained from ETEC F18-inoculated jejunal or ileal samples (PIOC experiment) were averaged per piglet before analysis.

The frequency of diarrhoea and alertness scores were analysed using the GLIMMIX procedure of SAS (SAS Institute)

Table 2. Sequences of primers and probes used in real-time PCR

\begin{tabular}{|c|c|c|}
\hline Targets & Primer sequences & Accession no. \\
\hline GAPDH & $\begin{array}{l}\text { Forward: 5'-GTCGGAGTGAACGGATTTGG-3' } \\
\text { Reverse: 5'-CAATGTCCACTTTGCCAGAGTTAA-3' } \\
\text { Probe: 5'-CGCCTGGTCACCAGGGCTGCT-3' }\end{array}$ & AF017079 \\
\hline$I L-10$ & $\begin{array}{l}\text { Forward: 5'-GAGGAGGTGAAGAGTGCCTTTA-3' } \\
\text { Reverse: 5'-CTCACCCATGGCTTTGTAGACA-3' } \\
\text { Probe: FAM-CCTCTCTTGGAGCTTGC-MGB }\end{array}$ & L20001 \\
\hline$T N F-\alpha$ & $\begin{array}{l}\text { Forward: } 5^{\prime} \text {-AACCCTCTGGCCCAAGGA-3' } \\
\text { Reverse: } 5^{\prime} \text {-GGCGACGGGCTTATCTGA-3' } \\
\text { Probe: FAM-TCAGATCATCGTCTCAAAC-MGB }\end{array}$ & X57321 \\
\hline IL-2 & $\begin{array}{l}\text { Forward: 5'-GATCTCTCCAGGATGCTCACATTT-3' } \\
\text { Reverse: 5'-CTCCAGAGCTTTGAGTTCTTCTACT-3' } \\
\text { Probe: FAM-CCCAAGCAGGCTACAGAA-MGB }\end{array}$ & X56750 \\
\hline $\operatorname{COX}-2$ & $\begin{array}{l}\text { Forward: } 5^{\prime} \text {-GGGACGATGAACGGCTGTT-3' } \\
\text { Reverse: } 5^{\prime} \text {-CACAATCTTAATCGTTTCTCCTATCAGT-3' } \\
\text { Probe: 5'-AGACGAGCAGGCTGA-3' }\end{array}$ & NM_214321 \\
\hline$T L R-4$ & $\begin{array}{l}20 \times \text { TagMan }^{\circledR} \text { Gene Expression Assay, catalogue } \\
\text { no. } 4331182 \text { (Applied Biosystems) }\end{array}$ & \\
\hline$T G F-\beta 1$ & $\begin{array}{l}20 \times \operatorname{TagMan}^{\circledR} \text { Gene Expression Assay, catalogue } \\
\text { no. } 4331182 \text { (Applied Biosystems) }\end{array}$ & \\
\hline
\end{tabular}


with treatment as a fixed effect and litter and pen as the random effects to account for the measurement being made in piglets from different litters and different pens. Data on performance and biliary Ig concentrations were analysed with a mixed model using the MIXED procedure of SAS with treatment and litter as the fixed and random effects, respectively. The remaining data that were obtained on various days (rectal temperature, LAB:E. coli ratio in faeces and plasma Ig concentrations) or from various segments of the gut (LAB: $E$. coli ratio in the digesta, number of $E$. coli colonising the intestine, mucosal Ig concentrations and gene expression levels) of the same piglet were analysed using the MIXED procedure with treatment and sampling day or gut/intestinal site as the fixed effects and litter as a random effect and taking into account that samples originated from the same animal. For data on rectal temperature and plasma Ig concentrations, which were obtained from piglets from different litters and pens, the random effects of litter and pen were imposed. The interaction between treatment and sampling day or gut/intestinal site was initially included in the model, but excluded when it was not statistically significant. Differences among the treatment groups were tested using the post hoc Tukey-Kramer test. Differences were considered significant when $P \leq 0 \cdot 05$. Results are presented as least-squares means and standard errors.

\section{Results}

\section{Growth performance and frequency of diarrhoea}

During the experiment, two piglets (from the BC-fed and MR-fed groups) died and so data obtained from these piglets were not included in the analyses. Piglets that were kept with the sows, i.e. the Sow-Milk group, exhibited a higher ( $P \leq 0.029$ ) weight gain compared with those separated from the sows and fed $\mathrm{BC}$ or MR (Table 3 ). The frequency of diarrhoea was higher $(P \leq 0.019)$ in MR-fed piglets than in BC-fed

Table 3. Growth performance and frequency of diarrhoea in piglets in response to the treatments

(Least-squares means with their standard errors)

\begin{tabular}{|c|c|c|c|c|c|}
\hline \multirow[b]{2}{*}{ Items } & \multicolumn{3}{|c|}{ Treatments } & \multirow[b]{2}{*}{$\mathrm{SE}$} & \multirow[b]{2}{*}{$P$} \\
\hline & BC-fed & MR-fed & Sow-Milk & & \\
\hline Weight gain $(\mathrm{g})^{\star}$ & $2024^{a}$ & $3023^{a}$ & $6440^{b}$ & 1649 & 0.023 \\
\hline Milk intake $(\mathrm{g})^{\star}$ & 2981 & 4767 & NR & 1835 & 0.133 \\
\hline Pig days† & 44 & 44 & 48 & & \\
\hline $\begin{array}{c}\text { Frequency of } \\
\text { diarrhoeał }\end{array}$ & $5^{a}$ & $18^{\mathrm{b}}$ & $3^{a}$ & & 0.008 \\
\hline
\end{tabular}

BC-fed, piglets separated from the sow and fed bovine colostrum; MR-fed, piglets separated from the sow and fed a commercial milk replacer; Sow-Milk, piglets kept with the sow; NR, not recorded.

${ }^{a, b}$ Values within a row with unlike superscript letters were significantly different $(P \leq 0.05)$.

* Data presented are the weight gain and milk intake recorded in each pen throughout the experimental period. BC-fed, $n 3$ pens; MR-fed, $n 3$ pens; Sow-Milk, $n 4$ pens. Data collected from pens with only two piglets (due to the death of one piglet) were not included in the statistical analyses.

$\dagger$ Pig days $=$ number of piglets $\times$ number of days of diarrhoea scoring. BC-fed, $n 11$ piglets; MR-fed, $n 11$ piglets; Sow-Milk, $n 12$ piglets. Diarrhoea scoring was conducted on days $1,3,5$ and 8 of the experiment.

$\ddagger$ Frequency of diarrhoea $=$ number of pig days with diarrhoea score $>3$. and Sow-Milk piglets (Table 3). There were no significant differences with regard to the alertness of piglets throughout the experiment (data not shown). The rectal temperature did not differ significantly among the treatment groups throughout the experiment (ranged from 37 to $40^{\circ} \mathrm{C}$; data not shown).

\section{Ratios of lactic acid bacteria:Escherichia coli in the faeces and gastrointestinal digesta}

The ratios of LAB:haemolytic E. coli and LAB:total coliform bacteria in the faeces and GIT digesta of piglets are shown in Figs. 1 and 2, respectively. The LAB:haemolytic E. coli ratio was higher $\left(P_{\text {day }}=0.029\right)$ during the first $3 \mathrm{~d}$ of the experiment than in the remaining $5 \mathrm{~d}$ and tended $\left(P_{\text {treat }}=0.064\right)$ to be lower in the faeces of MR-fed piglets than in that of BC-fed and Sow-Milk piglets. The Base and Sow-Milk piglets had a higher LAB: coliform bacteria ratio in the digesta collected from the small intestine when compared with MR-fed piglets ( $P \leq 0.043)$, but exhibited no differences when compared with BC-fed piglets. The LAB:haemolytic E. coli ratio in the gastrointestinal digesta of MR-fed piglets exhibited a decreasing tendency $\left(P_{\text {treat }}=0.068\right)$ when compared with that in piglets from the other treatment groups.

\section{Number of Escherichia coli colonising the intestinal tissue}

The number of E. coli colonising the jejunal and ileal tissue and content is summarised in Table 4. The number of $E$. coli was higher $(P \leq 0.039)$ in the jejunal and ileal tissue and content in the non-inoculated intestinal samples of MR-fed piglets than in the samples of BC-fed and Sow-Milk piglets. The number of $E$. coli was higher $\left(P_{\text {seg }}<0.001\right)$ in the ileal tissue and content than in the jejunal tissue and content. The number of $E$. coli colonising the intestinal tissue in the ETEC F18-inoculated jejunal and ileal samples of BC-fed piglets was lower than that in the samples of MR-fed piglets, but there were no significant differences in values $\left(P_{\text {treat }}=0.320\right)$

\section{Ig concentrations in the intestinal mucosa, bile and plasma}

The concentrations of total Ig in the intestinal mucosa and bile of piglets are given in Table 5. Piglets from the Sow-Milk group had a higher $(P=0 \cdot 020)$ concentration of $\operatorname{IgG}$ in the mucosa when compared with piglets from the MR-fed group, but did not exhibit any difference when compared with piglets from the Base and BC-fed groups. The concentration of mucosal IgA was found to be influenced by the interaction between treatment and intestinal segment $\left(P_{\text {treat } \times \text { seg }}=0.087\right)$, as evidenced by the higher concentrations of IgA in the jejunum and ileum of Base piglets than in those of piglets from the other treatment groups. Piglets from the MR-fed group had a lower $(P=0 \cdot 051)$ concentration of total IgM in the mucosa when compared with those from the Base group, but did not exhibit any difference when compared with piglets from the BC-fed and Sow-Milk groups. Regardless of treatment, the concentration of total IgM was higher $(P \leq 0.045)$ in the ileum than in the duodenum or jejunum, while that of IgA was higher $(P=0.034)$ in the ileum than 

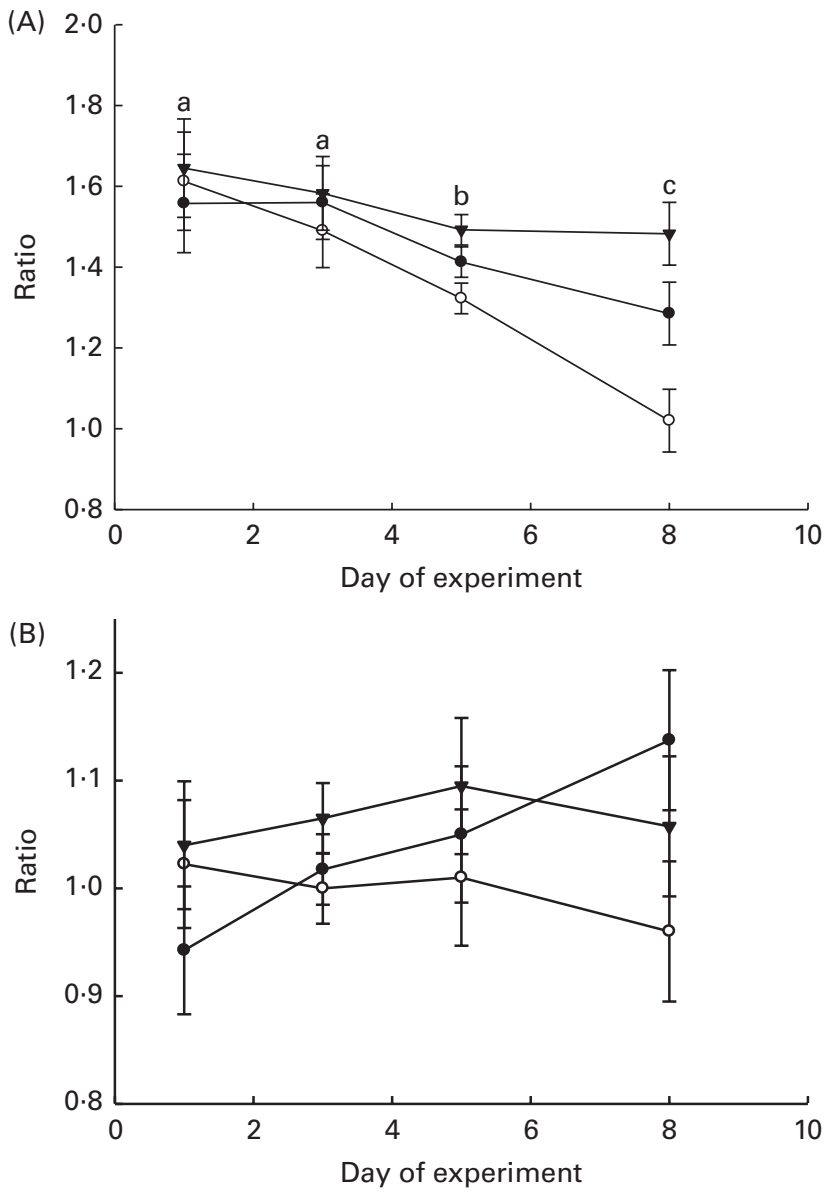

Fig. 1. Lactic acid bacteria:haemolytic Escherichia coli ratio (A) and lactic acid bacteria:total coliform bacteria ratio (B) in the faeces of piglets. Values are least-squares means, with their standard errors represented by vertical bars. ${ }^{a, b, c}$ Mean values with unlike letters were significantly different $(P \leq 0.05)$. Four piglets were analysed per treatment and day of experiment (faecal sampling). BC-fed (-0-), piglets separated from the sow and fed bovine colostrum; MR-fed (-O-), piglets separated from the sow and fed a commercial milk replacer; Sow-Milk $(-\nabla-)$, piglets kept with the sow. (A) $P_{\text {treat }}=0.064 ; P_{\text {day }}=0.029 ; P_{\text {treat } x \text { day }}=0.325$. (B) $P_{\text {treat }}=0.143$; $P_{\text {day }}=0.784 ; P_{\text {treat } \times \text { day }}=0.626$.

in the duodenum, but did not differ from that in the jejunum. No significant differences were observed with regard to the concentrations of $\operatorname{IgA}(P=0.236)$ and $\operatorname{IgM}(P=0.062)$ in the bile of piglets; however, Base piglets tended $(P \leq 0.089)$ to have a lower concentration of IgM when compared with piglets from the other treatment groups.

There were no significant differences in the plasma concentrations of Ig among the treatment groups. Irrespective of the treatment, the concentration of IgG was lower $\left(P_{\text {day }}<0.001\right)$ on day 8 than on day 1 (Table 6).

\section{Gene expression levels in the intestinal mucosa}

Gene expression levels in the jejunal and ileal mucosa of piglets are shown in Fig. 3. The genes were expressed at higher $\left(P_{\text {seg }} \leq 0.010\right)$ levels in the ileal mucosa than in the jejunal mucosa, except for the $I L-2$ gene. The expression level of $T L R-4$ was lower $(P \leq 0.037)$ in the jejunal and ileal mucosa of Base and BC-fed piglets than in those of MR-fed and
Sow-Milk piglets. The expression level of $I L-2$ was higher $(P \leq 0.051)$ in the intestinal mucosa of piglets from the MRfed group than in that of piglets from the other treatment groups. Compared with that in piglets from the other treatment groups, the expression level of cyclo-oxygenase-2 $(C O X-2)$ was lower $(P \leq 0 \cdot 047)$ in the intestinal mucosa of Base piglets and was significantly higher in MR-fed piglets. The level of $I L-10$ expression was lower $(P \leq 0.036)$ in the intestinal mucosa of Base piglets than in that of MR-fed and Sow-Milk piglets, but did not differ from that in BC-fed piglets. No significant effect of treatment was observed on the expression levels of $T N F-\alpha$ and transforming growth factor$\beta 1(T G F-\beta 1)$.

Data on gene expression levels in the jejunal and ileal mucosa samples collected from the PIOC model were found to be invalid in the present study due to the inconsistent gene expression patterns measured. Compared with those in the control, gene expression levels in the mucosa of ETEC
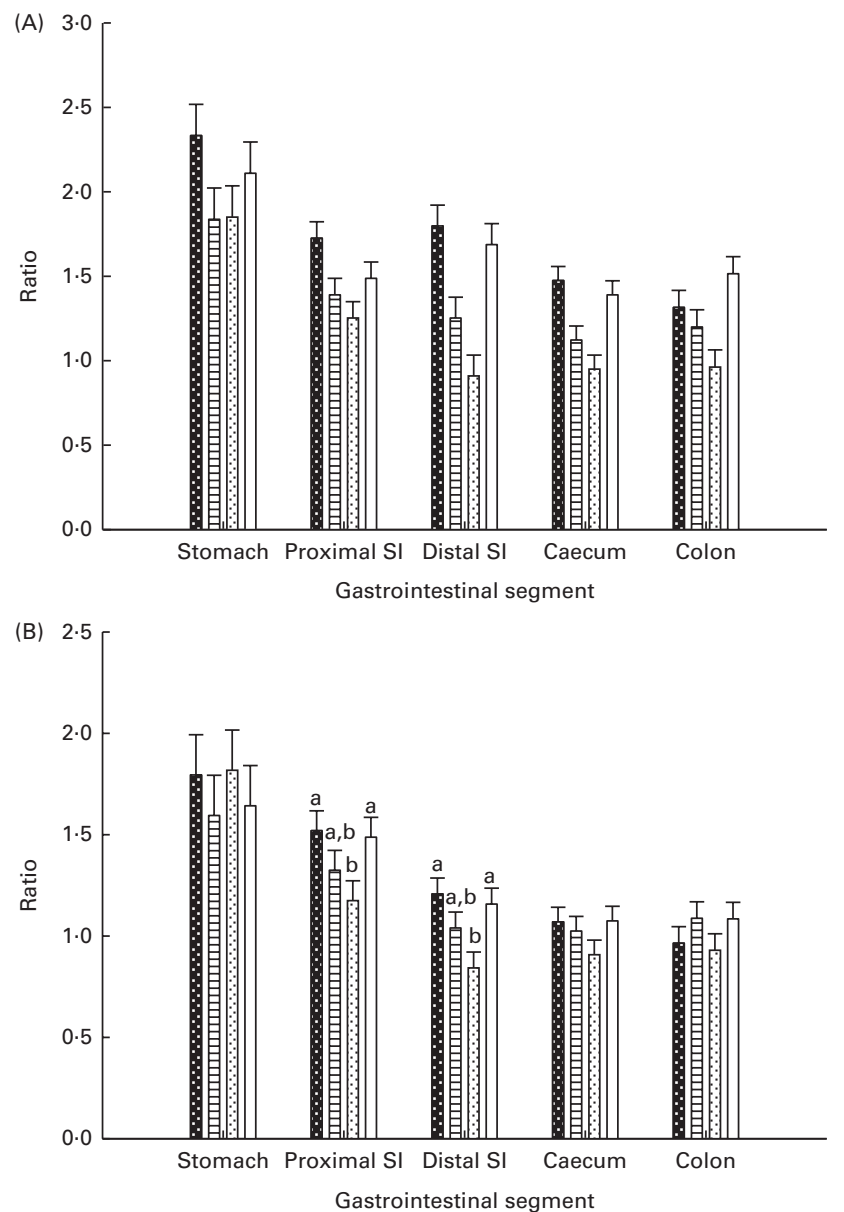

Fig. 2. Lactic acid bacteria:haemolytic $E$. coli ratio $(A)$ and lactic acid bacteria:total coliform bacteria ratio $(B)$ in the gastrointestinal digesta of piglets. Values are least-squares means, with their standard errors represented by vertical bars. ${ }^{a, b}$ Mean values with unlike letters were significantly different $(P \leq 0.05)$. Four piglets were analysed per treatment and gastrointestinal segment. Base ( $\mathbf{0})$, piglets killed at the beginning of the experiment; BC-fed (目), piglets separated from the sow and fed bovine colostrum; MR-fed (․).), piglets separated from the sow and fed a commercial milk replacer; Sow-Milk ( $\square$ ), piglets kept with the sow. SI, small intestine. (A) $P_{\text {treat }}=0.068 ; P_{\text {seg }}<0.001$; $P_{\text {treat } \times \text { seg }}=0.055$. (B) $P_{\text {treat }}=0.302 ; P_{\text {seg }}<0.001 ; P_{\text {treat } \times \text { seg }}=0.033$. 
Table 4. Number of Escherichia coli colonising the jejunal or ileal tissue and content in the porcine intestinal organ cultures of samples collected from the treated piglets

(Least-squares means with their standard errors)

\begin{tabular}{|c|c|c|c|c|c|c|c|}
\hline \multirow[b]{2}{*}{ Items } & \multicolumn{3}{|c|}{ Treatments* } & \multirow[b]{2}{*}{ SE } & \multicolumn{3}{|c|}{$P$} \\
\hline & BC-fed & MR-fed & Sow-Milk & & Treat & Seg & Treat $\times$ seg \\
\hline Non-inoculated tissue $(\log \mathrm{cfu} / \mathrm{g}) \dagger$ & & & & & $<0.001$ & $<0.001$ & 0.500 \\
\hline Jejunum & $4 \cdot 25^{\mathrm{a}}$ & $5 \cdot 91^{\mathrm{b}}$ & $4 \cdot 72^{\mathrm{a}}$ & 0.46 & & & \\
\hline Ileum & $6 \cdot 61^{\mathrm{a}}$ & $7 \cdot 65^{\mathrm{b}}$ & $6 \cdot 09^{\mathrm{a}}$ & 0.46 & & & \\
\hline Non-inoculated content $(\log \mathrm{cfu} / \mathrm{ml}) \dagger$ & & & & & 0.020 & $<0.001$ & 0.860 \\
\hline Jejunum & $3.52^{\mathrm{a}}$ & $5 \cdot 00^{\mathrm{b}}$ & $4 \cdot 00^{a}$ & 0.71 & & & \\
\hline Ileum & $6 \cdot 10^{\mathrm{a}}$ & $7 \cdot 20^{\mathrm{b}}$ & $6 \cdot 10^{\mathrm{a}}$ & 0.71 & & & \\
\hline E. coli-inoculated tissue $(\log \mathrm{cfu} / \mathrm{g}) \ddagger$ & & & & & 0.320 & 0.470 & 0.330 \\
\hline Jejunum & $7 \cdot 80$ & $8 \cdot 13$ & 7.57 & 0.33 & & & \\
\hline Ileum & 7.55 & $8 \cdot 27$ & $8 \cdot 18$ & 0.33 & & & \\
\hline E. coli-inoculated content $(\log \mathrm{cfu} / \mathrm{ml}) \ddagger$ & & & & & 0.590 & 0.070 & 0.450 \\
\hline Jejunum & 8.92 & 9.03 & $9 \cdot 13$ & 0.10 & & & \\
\hline Ileum & 8.89 & 8.91 & 8.92 & 0.10 & & & \\
\hline
\end{tabular}

BC-fed, piglets separated from the sow and fed bovine colostrum; MR-fed, piglets separated from the sow and fed a commercial milk replacer; Sow-Milk, piglets kept with the sow; Treat, treatment; Seg, segment of the small intestine; cfu, colony-forming units.

a,b Values within a row with unlike superscript letters were significantly different $(P \leq 0.05)$.

${ }^{*}$ Four piglets were analysed per treatment (of each small-intestinal site, one segment was not inoculated and two segments were inoculated with Escherichia coli $\mathrm{F} 18)$.

†Intestinal segments (collected from the treated piglets) were not inoculated with E. coli F18 during the porcine intestinal organ culture (PIOC) experiment.

¥Intestinal segments (collected from the treated piglets) were inoculated with E. coli F18 (8.96 (SE 0.29) log colony-forming units/ml for each segment) during the PIOC experiment.

F18-inoculated segments were higher, lower or similar, with no clear patterns. Therefore, the values are not reported or discussed here.

\section{Discussion}

About 3 weeks of age, piglets have the lowest concentrations of maternal antibodies acquired from the sow milk and their immune system is not as well developed as that of adults ${ }^{(7)}$. Thus, due to similarities, the use of 23 -d-old piglets in the present study could provide some information regarding weak piglets having an incompetent intestinal immune system. Indeed, at this age, piglets are also highly susceptible to ETEC F18, given that F18 receptors on porcine enterocytes are functionally active (F18 receptors are not yet fully active in piglets under about 3 weeks of age $)^{(19)}$. Several studies have reported positive effects of BC-supplemented diets on the immune responses of piglets ${ }^{(12,20)}$. In general, BC treatment was mainly used to provide additional Ig to weaned piglets following the loss of passive protection provided by the sow milk. However, data on the efficacy of BC supplements in enhancing antibody responses in piglets after

Table 5. Concentrations of total Ig in the intestinal mucosa and bile of piglets in response to the treatments (Least-squares means with their standard errors)

\begin{tabular}{|c|c|c|c|c|c|c|c|c|}
\hline \multirow[b]{2}{*}{ Items } & \multicolumn{4}{|c|}{ Treatments* } & \multirow[b]{2}{*}{ SE } & \multicolumn{3}{|c|}{$P$} \\
\hline & Base & BC-fed & MR-fed & Sow-Milk & & Treat & Seg & Treat $\times$ seg \\
\hline $\lg G(\mathrm{mg} / \mathrm{g})$ & & & & & & 0.030 & 0.963 & 0.268 \\
\hline Duodenum & $0.66^{a, b}$ & $0.85^{a, b}$ & $0.62^{a}$ & $0.80^{\mathrm{b}}$ & 0.27 & & & \\
\hline Jejunum & $0.93^{a, b}$ & $0.50^{\mathrm{a}, \mathrm{b}}$ & $0.86^{\mathrm{a}}$ & $0.74^{\mathrm{b}}$ & 0.24 & & & \\
\hline lleum & $0.60^{a, b}$ & $0.68^{a, b}$ & $0.36^{\mathrm{a}}$ & $1 \cdot 21^{\mathrm{b}}$ & 0.13 & & & \\
\hline $\lg A(\mathrm{mg} / \mathrm{g})$ & & & & & & 0.160 & 0.031 & 0.087 \\
\hline Duodenum & 1.88 & 1.85 & 1.92 & $3 \cdot 15$ & 0.47 & & & \\
\hline Jejunum & $13 \cdot 35$ & 1.43 & $1 \cdot 17$ & $2 \cdot 35$ & $3 \cdot 10$ & & & \\
\hline Ileum & 11.48 & $3 \cdot 15$ & $1 \cdot 80$ & 4.80 & $2 \cdot 11$ & & & \\
\hline $\operatorname{lgM}(\mathrm{mg} / \mathrm{g})$ & & & & & & 0.051 & 0.001 & 0.110 \\
\hline Duodenum & $1.73^{\mathrm{a}}$ & $2 \cdot 76^{a, b}$ & $4 \cdot 36^{\mathrm{b}}$ & $5 \cdot 41^{\mathrm{a}, \mathrm{b}}$ & 1.22 & & & \\
\hline Jejunum & $2 \cdot 23^{a}$ & $2 \cdot 34^{a, b}$ & $2.94^{\mathrm{b}}$ & $3 \cdot 34^{a, b}$ & 0.72 & & & \\
\hline Ileum & $8 \cdot 70^{a}$ & $5 \cdot 27^{a, b}$ & $3.98^{b}$ & $5 \cdot 41^{\mathrm{a}, \mathrm{b}}$ & 0.94 & & & \\
\hline Biliary $\lg \mathrm{A}(\mathrm{mg} / \mathrm{l})$ & 2.9 & 13.0 & 22.5 & $10 \cdot 8$ & 6.9 & 0.236 & & \\
\hline Biliary IgM (mg/l) & 1.4 & 4.9 & $6 \cdot 8$ & 4.6 & 1.5 & 0.062 & & \\
\hline
\end{tabular}

Base, Piglets killed at the beginning of the experiment; BC-fed, piglets separated from the sow and fed bovine colostrum; MR-fed, piglets separated from the sow and fed a commercial milk replacer; Sow-Milk, piglets kept with the sow; Treat, treatment; Seg, segment of the small intestine.

${ }^{a, b}$ Values within a row with unlike superscript letters were significantly different $(P \leq 0.05)$.

${ }^{\star}$ Four piglets were analysed per treatment and small-intestinal site. 
Table 6. Concentrations of total Ig in the plasma of piglets in response to the treatments (Least-squares means with their standard errors)

\begin{tabular}{|c|c|c|c|c|c|c|c|}
\hline \multirow[b]{2}{*}{ Items } & \multicolumn{3}{|c|}{ Treatments } & \multirow[b]{2}{*}{ SE } & \multicolumn{3}{|c|}{$P$} \\
\hline & BC-fed $(n 11)$ & MR-fed ( $(n 11)$ & Sow-Milk (n 12) & & Treat & Day & Treat $\times$ day \\
\hline $\lg G(\mathrm{mg} / \mathrm{l})$ & & & & & 0.606 & $<0.001$ & 0.944 \\
\hline Day 1 & 6120 & 5470 & 6020 & 640 & & & \\
\hline Day 8 & 3960 & 3440 & 3740 & 480 & & & \\
\hline $\operatorname{lgA}(\mathrm{mg} / \mathrm{l})$ & & & & & 0.719 & 0.173 & 0.877 \\
\hline Day 1 & 200 & 200 & 220 & 30 & & & \\
\hline Day 8 & 170 & 170 & 210 & 40 & & & \\
\hline $\lg M(\mathrm{mg} / \mathrm{l})$ & & & & & 0.447 & 0.194 & 0.892 \\
\hline Day 1 & 690 & 710 & 890 & 150 & & & \\
\hline Day 8 & 880 & 840 & 980 & 180 & & & \\
\hline
\end{tabular}

weaning have been inconsistent. Boudry et al. ${ }^{(12)}$ reported that oral supplementation with $\mathrm{BC}$ (piglets received $5 \mathrm{~g}$ of BC orally daily for 3 weeks) increased serum IgA concentrations (after 3 weeks of BC supplementation, but not before), but transiently decreased total $\operatorname{IgG}$ concentrations and had no influence on total IgM concentrations. In addition, total IgG, IgA and IgM concentrations in intestinal fluid samples were not affected by BC supplementation. In another study, Boudry et al. ${ }^{(20)}$ demonstrated that BC whey supplementation $(20 \mathrm{~g} / \mathrm{kg}$ of $\mathrm{BC}$ whey incorporated in the diet during the first 2 weeks after weaning and $10 \mathrm{~g} / \mathrm{kg}$ for the next 2 weeks) increased circulating IgA concentrations by $25 \%$ (during the 1st week after weaning, but not during the remaining experimental period) and had no impact on total IgG and IgM concentrations. Taking this into consideration, feeding a commercial BC preparation as the only dietary ingredient, rather than as a supplement, could be speculated to have beneficial effects on the immune responses of artificially reared weak piglets before weaning to a greater extent. It is known that the nutritional composition of diet, particularly protein, affects the immunocompetence of animals ${ }^{(21)}$. There was a substantial difference in the protein content of $\mathrm{BC}$ and that of the other two diets in the present study. Indeed, protein in $\mathrm{BC}$ is mainly composed of Ig ( $70-80 \%$ of the total protein content $)^{(4)}$ and hence any influence of $\mathrm{BC}$ on the immune system of piglets can reasonably be assumed to be due to $\mathrm{Ig}$ (and other immune factors such as cytokines) in BC.

In the present study, feeding a commercial $\mathrm{BC}$ product rather than a MR was found to have the capacity to reduce the frequency of diarrhoea in piglets and no differences were actually found in the frequency of diarrhoea in BC-fed piglets and SowMilk piglets. Corresponding results have been reported by Huguet et al. ${ }^{(22)}$, who found that feeding a BC-supplemented diet reduced diarrhoeal episodes in weaned piglets.

$\mathrm{BC}$ has been reported to contain growth factors essential for promoting the growth and development of newborn piglets ${ }^{(4)}$. Yet, feeding BC could not improve the growth performance of piglets in the present study, as evidenced by the finding that piglets staying with their dams gained more weight than those artificially reared on BC.
All piglets used in the present study were genetically susceptible to ETEC expressing F18 fimbriae. Previous studies have shown that $\mathrm{BC}$ exhibits antimicrobial activity through its functional components such as $\mathrm{Ig}^{(4,13)}$. In accordance with this, bacterial counts in the faecal and digesta samples revealed that feeding $\mathrm{BC}$ resulted in lower counts of haemolytic E. coli (indicator of ETEC) compared with feeding a commercial MR. The mean haemolytic E. coli count in the faeces was 5.97 (sE 0.72) log cfu/g in BC-fed piglets, 6.58 (sE 1.34) $\log \mathrm{cfu} / \mathrm{g}$ in MR-fed piglets and 5.87 (SE 0.42) $\log \mathrm{cfu} / \mathrm{g}$ in Sow-Milk piglets. The mean haemolytic E. coli count in the digesta across the GIT was 6.34 (SE 1.63) log cfu/g in BC-fed piglets, 7.05 (SE 1.90) $\mathrm{log} / \mathrm{cfu}$ in MR-fed piglets and 5.28 (SE 0.78$) \mathrm{log} / \mathrm{cfu}$ in Sow-Milk piglets. These values are within the normal range for haemolytic E. coli enumerated in the faeces and intestinal content of piglets after weaning ${ }^{(23,24)}$. Consistent with the bacterial counts in the faecal and GIT digesta samples, jejunal and ileal tissue samples collected from BC-fed (and Sow-Milk) piglets exhibited a significant reduction in the recovery of $E$. coli from the tissue when compared with samples collected from MRfed piglets. Data from the PIOC experiment also showed that, relatively to feeding a MR, feeding $\mathrm{BC}$ is associated with a lower colonisation of $E$. coli in the intestinal tissue after inoculation with ETEC F18. This is in agreement with the results of earlier studies reporting an inhibitory effect of $\mathrm{BC}$ on the adherence of enterohaemorrhagic E. coli and enteropathogenic $E$. coli to the intestinal mucosa of mice and HEp-2 cells, respectively ${ }^{(25,26)}$. In another in vitro study, pre-treatment with $\mathrm{BC}$ was found to decrease the attachment of Shiga toxin-producing E. coli O111 to colon-derived cell lines $(\mathrm{HT}-29)^{(27)}$. Altogether, we infer that BC is capable of inhibiting the attachment and/or colonisation of ETEC in the intestinal mucosa of piglets.

It has previously been shown that BC feeding could preserve the balanced microbiota in the intestine of piglets ${ }^{(4,28)}$. Accordingly, the results of the present study revealed that the LAB:haemolytic $E$. coli and LAB:coliform bacteria ratios in the faecal and digesta samples collected from BC-fed piglets were higher than those in samples collected from MR-fed piglets. This further provides an indication that BC is capable 

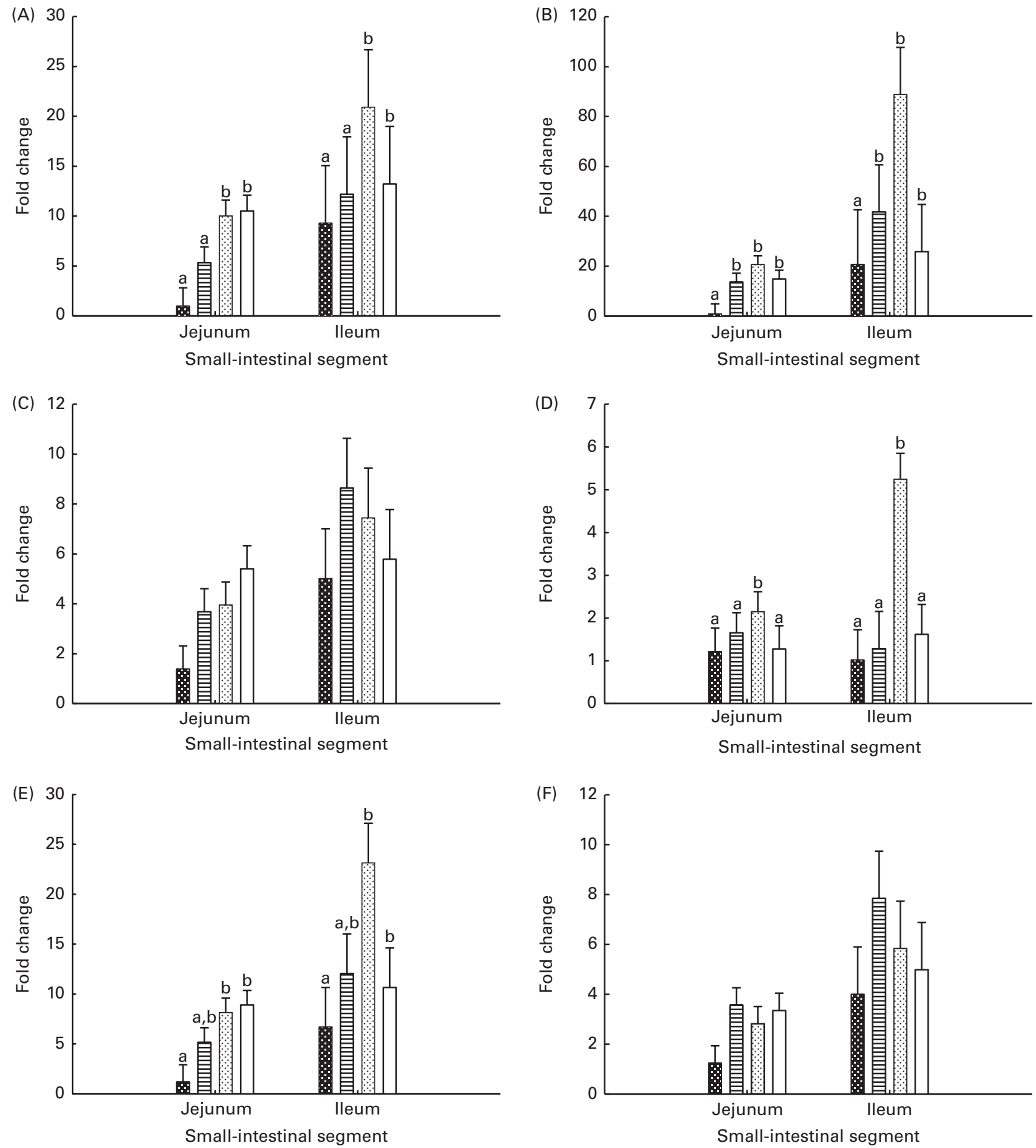

Fig. 3. Gene expression levels of Toll-like receptor-4 (A), cyclo-oxygenase-2 (B), TNF- $\alpha(C), I L-2(D), I L-10(E)$ and transforming growth factor- $\beta 1$ (F) in the intestinal mucosa of piglets. Values are least-squares means with their standard errors represented by vertical bars. ${ }^{a, b}$ Mean values with unlike letters were significantly different $(P \leq 0.05)$. Four piglets were analysed per treatment and small-intestinal segment. Base (圈), piglets killed at the beginning of the experiment; BC-fed (目), piglets separated from the sow and fed bovine colostrum; MR-fed (因), piglets separated from the sow and fed a commercial milk replacer; Sow-Milk ( $\square$ ), piglets kept with the sow. (A) $P_{\text {treat }}=0.011 ; P_{\text {seg }}=0.010 ; P_{\text {treat } \times s e g}=0.726$. (B) $P_{\text {treat }}=0.046 ; P_{\text {seg }}=0.007 ; P_{\text {treatxseg }}=0.183$. (C) $P_{\text {treat }}=0.100 ; P_{\text {seg }}=0.009$; $P_{\text {treat } \times \text { seg }}=0.500$. (D) $P_{\text {treat }}=0.009 ; P_{\text {seg }}=0.171 ; P_{\text {treat } \times \text { seg }}=0.074$. (E) $P_{\text {treat }}=0.022 ; P_{\text {seg }}=0.005 ; \quad P_{\text {treat } \times \text { seg }}=0.191$. (F) $P_{\text {treat }}=0.161 ; P_{\text {seg }}=0.002 ;$ $P_{\text {treat } \times \text { seg }}=0.720$.

of inhibiting the growth of coliform bacteria and ETEC in the gut of piglets. The results also revealed that the LAB: haemolytic $E$. coli ratio in the faeces decreased with time after experimental treatment. However, the decrease was mainly observed in piglets that were separated from the sows, suggesting that separation from the sows altered the balanced gut microbiota in piglets. As has been observed in the present study, previous studies have reported that the number of enteric bacterial pathogens increase, whereas LAB population levels are suppressed after weaning ${ }^{(4,10,29)}$. 
As has been discussed above, BC is an important source of Ig that may provide the host with passive immunity against infectious pathogens ${ }^{(4,13)}$. In the present study, the concentrations of $\mathrm{Ig}$ in the $\mathrm{BC}$ were much higher than those in the sow milk and MR. Yet, the resulting concentrations of Ig in the mucosa of BC-fed piglets did not differ significantly from those in the mucosa of MR-fed or Sow-Milk piglets. Similar results were reported by Boudry et $a l^{(12)}$, as has been mentioned above. The inability of porcine Ig receptors on the surface of enterocytes to efficiently bind to the bovine $\mathrm{Ig}^{(30)}$ may explain this finding. The bovine colostral Ig that are not absorbed by the intestine (remaining in the intestinal lumen) may, however, still provide passive local immunity to piglets by binding to the antigens and protecting the intestinal tissue through immune exclusion ${ }^{(13)}$. In the present study, feeding $\mathrm{BC}$ to the piglets did not result in differences in terms of circulatory Ig concentrations. The low capacity of the intestine to absorb bovine $\operatorname{Ig}^{(30)}$ and/or gut closure ${ }^{(12,31)}$ may explain the poor transfer of bovine Ig from the gut to the bloodstream in piglets during the period after separation from the sows. Irrespective of the treatment, the concentration of plasma $\operatorname{IgG}$ was higher on day 1 than on day 8 of the experiment. The decrease in total plasma IgG concentrations could be associated with the age effect or decay of passively acquired maternal $\operatorname{IgG}^{(12)}$. In accordance with the systemic Ig, the concentrations of total IgA were higher in the jejunal and ileal mucosa of piglets from the Base group, killed at the beginning of the experiment, than in that of piglets from the other treatment groups, which were killed $8 \mathrm{~d}$ later.

Changes in the diet and environment of piglets after separation from the sows have been known to be associated with an increased number of pathogenic bacteria in the various regions of the $\mathrm{GIT}^{(10)}$. Through $\mathrm{TLR}$, these bacteria are able to produce signals that up-regulate the expression of pro-inflammatory factors and stimulate host immune responses ${ }^{(32)}$. In the present study, $\mathrm{BC}$ was able to reduce the intestinal colonisation by ETEC and, accordingly, the increased expression of TLR-4 was not observed in the intestinal mucosa of BC-fed piglets. The release of cytokines or other inflammatory factors upon recognition of Gram-negative pathogenic bacteria is one of the most important effects of TLR- 4 activation $^{(32)}$. In the case of BC-fed piglets, a low activation of TLR- 4 by ETEC may therefore be implicated in the lower expression of pro-inflammatory mediators, apparently as in the lower expression levels of $I L-2$ (inflammatory mediators in response to bacterial infections ${ }^{(33)}$ ) in the intestinal mucosa. TNF- $\alpha$ is an inflammatory cytokine that is normally up-regulated upon antigen stimulation ${ }^{(27)}$. Unlike those of $I L-2$, the expression levels of $T N F-\alpha$ in the intestinal mucosa did not differ among the treatment groups in the present study. BC is known to contain several potential proinflammatory components, including TNF- $\alpha$ and IL- ${ }^{(4)}$. Therefore, pre-treatment with $\mathrm{BC}$ increases the production of TNF- $\alpha$ and IL- 6 in both antigen-stimulated and unstimulated human monocytic THP-1 cells (ATCCIIB-202) ${ }^{(27)}$. Many immunomodulatory factors such as TNF- $\alpha$ and IL-10 are also present in the sow milk $^{(5)}$. Taken together, the potential of $\mathrm{BC}$ and sow milk to up-regulate the expression of $T N F-\alpha$ may therefore explain the lack of difference in the expression levels of this cytokine among the treatment groups, although the small intestine of BC-fed and SowMilk piglets was less colonised by the E. coli compared with that of MR-fed piglets. IL-10 is an anti-inflammatory cytokine that plays a critical immunoregulatory role (balances immune activation) during immune responses. There are diverse stimuli that can induce the production of this cytokine, among which are bacteria and bacterial products (enterotoxins) ${ }^{(34)}$. Concomitant with that of $I L-1 O$, the expression of $T G F-\beta 1$, which is an essential signal for the generation of regulatory $\mathrm{T}$ cells and T-helper 17 cells, is induced by bacterial infections ${ }^{(35)}$. In conjunction with the higher population levels of $E$. coli in the intestine of MR-fed piglets that might lead to higher expression levels of $I L-1 O$ and $T G F-\beta 1$ in the mucosa, the presence of IL- $10^{(5)}$ and TGF- $\beta 1^{(4,5)}$ in the BC and sow milk appeared to be responsible for the increased expression levels of these immune mediators in the intestinal mucosa of $\mathrm{BC}$ and sow milk-fed piglets ${ }^{(36)}$. This condition may explain the insignificant differences in $I L-10$ and TGF- $\beta 1$ expression levels among the treatment groups in the present study.

An interesting finding from the present study is that genes (TLR-4, COX-2, TNF- $\alpha, I L-10$ and TGF- $\beta 1$ ) were expressed at higher levels in the ileal mucosa than in the jejunal mucosa of piglets, irrespective of the treatment. Consistent with this, the concentrations of total IgA and IgM were higher in the ileal mucosa than in the jejunal mucosa. Based on data from the PIOC experiment, in which more E. coli were enumerated in ileal tissue than in jejunal tissue, we infer that the immune responses may partly be affected by the degree of colonisation of bacterial pathogens in the gut. This is in accordance with the results of studies of Wang et $a l^{(35)}$ and Daudelin et al. ${ }^{(37)}$, who reported that the colonisation of $E$. coli or other bacterial pathogens in the intestine is responsible for the stimulation of the host-related immune responses.

In conclusion, feeding $\mathrm{BC}$ to the piglets reduced the intestinal colonisation of ETEC and modulated the intestinal mucosal immune system when compared with feeding a MR. Rearing piglets on $\mathrm{BC}$ was as good as conventional rearing by sows in terms of optimisation of the immune defence of weak piglets. Hence, future research should consider the potential of $\mathrm{BC}$ supplementation in weak piglets.

\section{Acknowledgements}

The authors thank Malene Cilieborg, KU-Life (Copenhagen University), Denmark, for providing the E. coli strain O138:F18. They also thank Karin Durup and Inger-Marie Jepsen for their technical assistance during the experiment and Mette Lykkegaard Jørgensen and Karin Johansen for their assistance with the animal care.

Funding for the present study was received through the NEOMUNE Centre ('Early milk and microbiota to stimulate later immunity') by The Danish Council for Strategic Research and the Graduate School of Science and Technology, Aarhus 
University, Denmark, for a PhD scholarship (A.-S. R. P.) and through a $\mathrm{PhD}$ scholarship received from the Ministry of Education and Culture, Republic of Indonesia (S. S.). The funders had no role in the design or analysis of the study and in the writing of this manuscript.

Trade names or commercial products have been mentioned in the article simply for the purpose of providing specific information and not for recommendation or endorsement purposes.

The authors' contributions are as follows: S. S. conducted the animal trial, carried out the sample analyses, analysed the data and drafted the manuscript; A.-S. R. P. conducted the animal trial and revised the drafted manuscript; N. C. contributed to the study design, conducted the animal trial, assisted with the data analyses and revised the drafted manuscript; C. L. was the project co-ordinator, designed the experiment and revised the drafted manuscript.

None of the authors has any conflicts of interest to declare.

\section{References}

1. Rutherford KMD, Baxter EM, D'Eath RB, et al. (2013) The welfare implications of large litter size in the domestic pig I: biological factors. Anim Welfare 22, 199-218.

2. Wolf J, Žáková E \& Groeneveld E (2008) Within-litter variation of birth weight in hyperprolific Czech Large White sows and its relation to litter size traits, stillborn piglets and losses until weaning. Livest Sci 115, 195-205.

3. De Vos M, Huygelen V, Willemen S, et al. (2014) Artificial rearing of piglets: effects on small intestinal morphology and digestion capacity. Livest Sci 159, 165-173.

4. Boudry C, Dehoux J-P, Portetelle D, et al. (2008) Bovine colostrum as a natural growth promoter for newly weaned piglets: a review. Biotechnol Agron Soc Environ 12, 157-170.

5. Nguyen TV, Yuan L, Azevedo MS, et al. (2007) Transfer of maternal cytokines to suckling piglets: in vivo and in vitro models with implications for immunomodulation of neonatal immunity. Vet Immunol Immunopathol 117, 236-248.

6. Zimmerman JJ, Karriker LA, Ramirez A, et al. (2012) Diseases of Swine, 10th ed. West Sussex: Blackwell Publishing.

7. Pluske JR, Dividich JL \& Verstegen MWA (2003) Weaning the Pig: Concepts and Consequences. Wageningen: Wageningen Academic Publishers.

8. Roese G \& Taylor G (2006) Basic pig husbandry - the litter. Primefact 71. http://www.dpi.nsw.gov.au/_data/assets/ pdf_file/0018/56142/Basic_pig_husbandry-The_litter_-_Pri mefact_71-final.pdf (accessed June 2014).

9. Cabrera RA, Boyd RD, Jungst SB, et al. (2010) Impact of lactation length and piglet weaning weight on long-term growth and viability of progeny. J Anim Sci 88, 2265-2276.

10. Heo JM, Opapeju FO, Pluske JR, et al. (2013) Gastrointestinal health and function in weaned pigs: a review of feeding strategies to control post-weaning diarrhoea without using in-feed antimicrobial compounds. J Anim Physiol Anim Nutr 97, 207-237.

11. Miller YJ, Collins AM, Smits RJ, et al. (2012) Providing supplemental milk to piglets preweaning improves the growth but not survival of gilt progeny compared with sow progeny. J Anim Sci 90, 5078-5085.

12. Boudry C, Buldgen A, Portetelle D, et al. (2007) Effects of oral supplementation with bovine colostrum on the immune system of weaned piglets. Res Vet Sci 83, 91-101.
13. Hurley WL \& Theil PK (2011) Perspectives on immunoglobulins in colostrum and milk. Nutrients 3, 442-474.

14. Carstensen L, Ersbøll AK, Jensen KH, et al. (2005) Escherichia coli post-weaning diarrhoea occurrence in piglets with monitored exposure to creep feed. Vet Microbiol 110, 113-123.

15. Frydendahl K, Jensen TK, Andersen JS, et al. (2003) Association between the porcine F18 receptor genotype and phenotype and susceptibility to colonisation and postweaning diarrhoea caused by O138:F18. Vet Microbiol 93, 39-51.

16. Naughton PJ, Mikkelsen LL \& Jensen BB (2001) Effects of nondigestible oligosaccharides on Salmonella enterica serovar Typhimurium and nonpathogenic Escherichia coli in the pig small intestine in vitro. Appl Environ Microbiol 67, 3391-3395.

17. Sugiharto S, Jensen BB \& Lauridsen C (2012) Development of an ex vivo model for investigating the bacterial association to the gut epithelium of pigs. J Anim Sci 90, Suppl. 4, 397-399.

18. Holdeman LV, Cato EP \& Moore EC (1977) Anaerobe Laboratory Manual, 4th ed. Blacksburg, VA: Virginia Polytechnic Institute and State University.

19. Coddens A, Verdonck F, Tiels P, et al. (2007) The agedependent expression of the $\mathrm{F} 18^{+} E$. coli receptor on porcine gut epithelial cells is positively correlated with the presence of histo-blood group antigens. Vet Microbiol 122, 332-341.

20. Boudry C, Dehoux J-P, Wavreille J, et al. (2008) Effect of a bovine colostrum whey supplementation on growth performance, faecal Escherichia coli population and systemic immune response of piglets at weaning. Animal 2, 730-737.

21. Li P, Yin Y-L, Li D, et al. (2007) Amino acids and immune function. BrJ Nutr 98, 237-252.

22. Huguet A, Le Dividich J \& Le Huërou-Luron I (2012) Improvement of growth performance and sanitary status of weaned piglets fed a bovine colostrum-supplemented diet. I Anim Sci 90, 1513-1520.

23. Kiarie E, Bhandari S, Scott M, et al. (2011) Growth performance and gastrointestinal microbial ecology responses of piglets receiving Saccharomyces cerevisiae fermentation products after an oral challenge with Escherichia coli (K88). J Anim Sci 89, 1062-1078.

24. Jensen KH, Damgaard BM, Andresen LO, et al. (2013) Prevention of post weaning diarrhoea by a Saccharomyces cerevisiae-derived product based on whole yeast. Anim Feed Sci Technol 183, 29-39.

25. Palmeira P, Carbonare SB, Silva MLM, et al. (2001) Inhibition of enteropathogenic Escherichia coli (EPEC) adherence to HEp- 2 cells by bovine colostrum and milk. Allergol Immunopathol 29, 229-237.

26. Funatogawa K, Ide T, Kirikae F, et al. (2002) Use of immunoglobulin enriched bovine colostrum against oral challenge with enterohaemorrhagic Escherichia coli $\mathrm{O} 157: \mathrm{H} 7$ in mice. Microbiol Immunol 46, 761-766.

27. Brooks HJL, McConnell MA, Corbett J, et al. (2006) Potential prophylactic value of bovine colostrum in necrotizing enterocolitis in neonates: an in vitro study on bacterial attachment, antibody levels and cytokine production. FEMS Immunol Med Microbiol 48, 347-354.

28. Huguet A, Sève B, Le Dividich J, et al. (2006) Effects of a bovine colostrum-supplemented diet on some gut parameters in weaned piglets. Reprod Nutr Dev 46, 167-178.

29. Lallès JP, Bosi P, Smidt H, et al. (2007) Weaning - a challenge to gut physiologist. Livest Sci 108, 82-93. 
30. Drew MD \& Owen BD (1988) The provision of passive immunity to colostrum-deprived piglets by bovine or porcine serum immunoglobulins. Can J Anim Sci 68, 1277-1284.

31. Sangild PT (2003) Uptake of colostral immunoglobulins by the compromised newborn farm animal. Acta Vet Scand 98, Suppl. 1, 105-122.

32. Netea MG, Van der Meer JWM, Sutmuller RP, et al. (2005) From the Th1/Th2 paradigm towards a Toll-like receptor/T-helper bias. Antimicrob Agents Chemother 49 , 3991-3996.

33. de Rham C, Ferrari-Lacraz S, Jendly S, et al. (2007) The proinflammatory cytokines IL-2, IL-15 and IL-21 modulate the repertoire of mature human natural killer cell receptors. Arthritis Res Ther 9, R125.

34. van der Poll T, Marchunt A \& van Deventer SJH (1997) The role of interleukin-10 in the pathogenesis of bacterial infection. Clin Microbiol Infect 3, 605-607.

35. Wang B, Dileepan T, Briscoe S, et al. (2010) Induction of TGF- $\beta 1$ and TGF- $\beta 1$-dependent predominant Th17 differentiation by group A streptococcal infection. Proc Natl Acad Sci U S A 107, 5937-5942.

36. Shing CM, Peake JM, Suzuki K, et al. (2009) Bovine colostrum modulates cytokine production in human peripheral blood mononuclear cells stimulated with lipopolysaccharide and phytohemagglutinin. J Interferon Cytokine Res 29, $37-44$.

37. Daudelin J-F, Lessard M, Beaudoin F, et al. (2011) Administration of probiotics influences F4 (K88)-positive enterotoxigenic Escherichia coli attachment and intestinal cytokine expression in weaned pigs. Vet Res 42, 69.

38. Lauridsen C \& Danielsen V (2004) Lactational dietary fat levels and source influence milk composition and performance of sows and their progeny. Livest Prod Sci $\mathbf{9 1}$, 95-105.

39. Aguinaga MA, Gómez-Carballar F, Nieto R, et al. (2011) Production and composition of Iberian sow's milk and use of milk nutrients by the suckling Iberian piglet. Animal 5, 1390-1397. 